\title{
Isolated Hypoglossal Nerve Palsy Caused by Neurovascular Compression
}

\author{
Masanari Yamamoto, Keisuke Suzuki, Hidehiro Takekawa and Koichi Hirata
}

Key words: isolated hypoglossal nerve palsy, MRI, slowly progressive course

(Intern Med 50: 2701-2702, 2011)

(DOI: 10.2169/internalmedicine.50.6209)

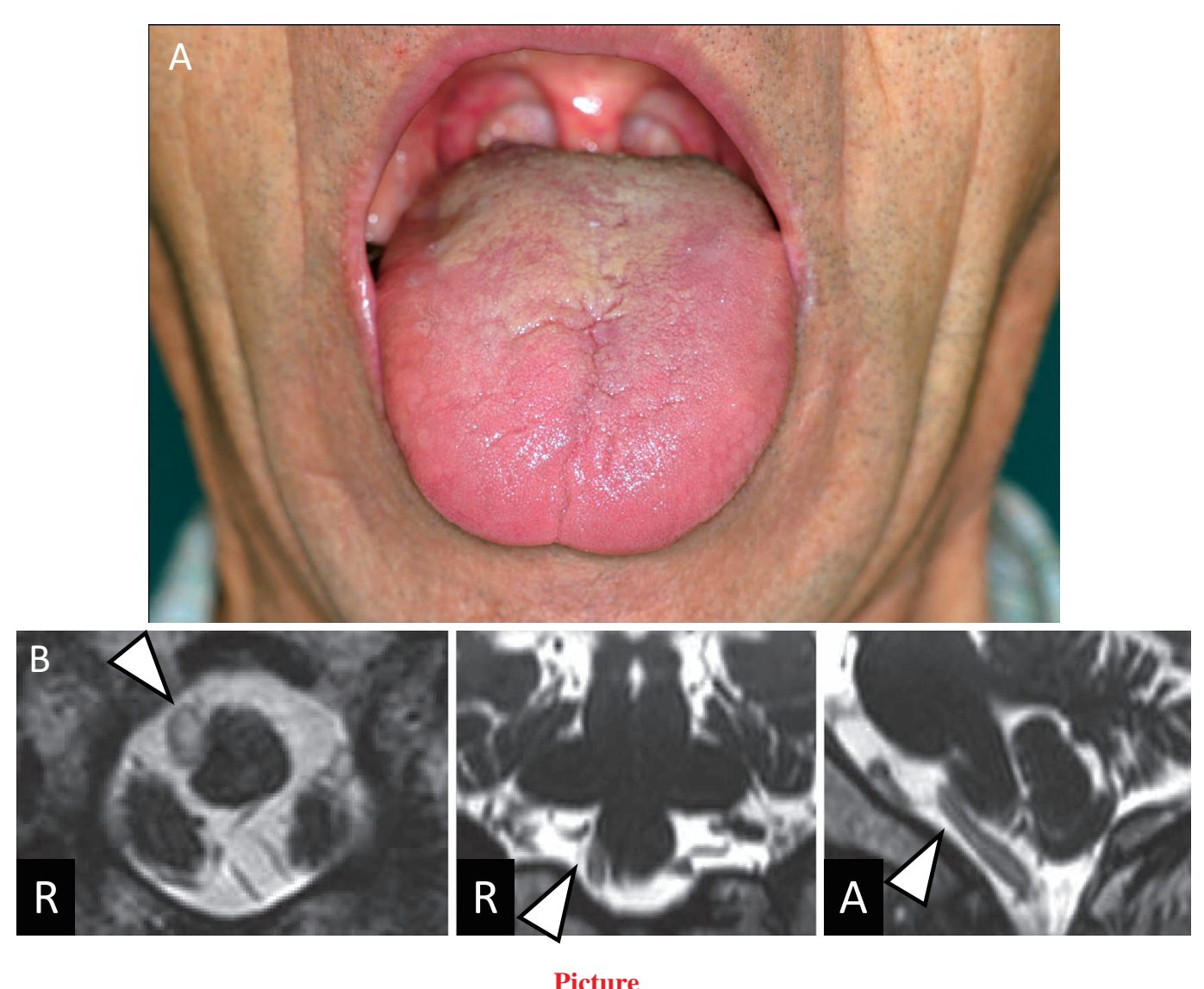

An 80-year-old man presented with difficulty in swallowing and speaking which had progressed over one year. Neurological examination revealed right hypoglossal nerve palsy with ipsilateral atrophy (Picture A). Laryngoscopic examination was unremarkable. Slowly progressive dysarthria and dysphagia with tongue atrophy initially indicated motor neuron disease (MND), but needle electromyographic examination did not show neurogenic changes consistent with MND. Brain MRI showed mild deep white matter lesions without space occupying lesions. Constructive interference in steady state (CISS) MRI showed right vertebral artery compression in the medulla oblongata, which corresponded to the exit of the right hypoglossal nerve (Picture B). The indication for surgical decompression is currently under consideration. Although isolated hypoglossal nerve palsy can be caused by different etiologies (1), neurovascular compression is an important cause, given that microvascular decompression can resolve hypoglossal nerve palsy (2). Physicians should be 
aware of the possibility of neurovascular compression in a patient showing isolated hypoglossal nerve palsy in a slowly progressive manner.

The authors state that they have no Conflict of Interest (COI).

\section{References}

1. Boban M, Brinar VV, Habek M, Rados M. Isolated hypoglossal nerve palsy: a diagnostic challenge. Eur Neurol 58: 177-181, 2007.

2. Cheong JH, Kim JM, Yang MS, Kim CH. Resolution of isolated unilateral hypoglossal nerve palsy following microvascular decompression of the intracranial vertebral artery. J Korean Neurosurg Soc 49: 167-170, 2011.

\footnotetext{
(C) 2011 The Japanese Society of Internal Medicine http://www.naika.or.jp/imindex.html
} 